\title{
Attitudes towards and knowledge about intrauterine contraceptive devices among women in the reproductive age group in a resource-constrained setting
}

\author{
P Monji Builu, MB ChB, Dip Obst, Dip HIV Man, PGDip Public Health; T D Naidoo, FCOG, PhD \\ Department of Obstetrics and Gynaecology, Grey's Hospital, Pietermaritzburg, and Nelson Mandela School of Medicine, \\ College of Health Sciences, University of KwaZulu-Natal, Durban, South Africa
}

Corresponding author: P Monji Builu (pierrotbwilu@gmail.com)

\begin{abstract}
Background. One of the strategies to reduce maternal mortality includes accessible and appropriate contraceptive services to all women. The intrauterine contraceptive device (IUCD) has been identified as a cheap and effective means of contraception by the South African National Department of Health.

Objective. To explore knowledge about the IUCD among women using the public health sector and identify any misconceptions.

Methods. A sample of 150 women attending antenatal/postnatal clinics were interviewed using a structured questionnaire.

Results. Forty-six percent $(n=69)$ had some experience with the injectable form of contraception, and $2.7 \%(n=4)$ had used the IUCD; $70.7 \%(n=106)$ knew that the device does not prevent HIV transmission, 40.7\% ( $n=61)$ knew that HIV-positive women can use the IUCD, $75.3 \%$ ( $n=113$ ) believed that the IUCD causes heavy bleeding, 36.7\% $(n=55)$ knew that the device does not stop fertility indefinitely, 33.3\% $(n=50)$ knew that the IUCD can be inserted in the immediate postpartum period, and $26.7 \%(n=40)$ knew that the duration of use is 10 years. In terms of attitudes, $40.0 \%(n=60)$ expressed concern about the pain during insertion, $33.3 \%(n=50)$ believed the IUCD can cause cancer, and $32.0 \%(n=48)$ believed that the device interferes with normal sexual activity. Most participants $77.3 \%(n=116)$ acquired the information they had about the IUCD from the clinic during teaching and counselling sessions.

Conclusion. This survey documented poor knowledge about the IUCD among women using the public health sector. However, the fact that there are few misconceptions and that clients rely on the clinic information should be seen as an opportunity to improve the situation.
\end{abstract}

S Afr J Obstet Gynaecol 2015;21(2):27-32. DOI:10.7196.SAJOG.950

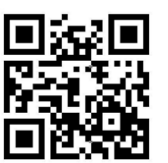

The rate of unplanned pregnancies remains high worldwide, including in South Africa (SA). Despite reported high contraceptive use, nearly $40 \%$ of women are at risk of unintended pregnancy. ${ }^{[1]}$ In 2008 Frost and Darroch ${ }^{[2]}$ reported that $38 \%$ of participants in their study had missed at least one active pill in the previous 3 months, and pregnancies among contraceptive users accounted for nearly half of all unintended pregnancies and were almost entirely due to inconsistent or incorrect contraceptive use. Credé et al. ${ }^{[3]}$ in 2009 also reported that the majority of women had unplanned pregnancies, despite a high rate of use of contraception, and with no difference according to HIV status.

Unintended pregnancies result in an increase in rates of abortion, both legal and illegal. The SA Department of Health reported an increase in the rate of abortion, despite the fact that modern contraceptives are available and free in the public sector. ${ }^{[4]}$ Patel and Kooverjee ${ }^{[5]}$ also found that the rate of abortion among young women in SA has continued to increase despite the availability of contraception, and that inconsistent contraceptive use was the main reason for unwanted pregnancy. Success in preventing unintended pregnancies requires long periods of effective contraceptive use.

Women who choose long-acting methods are least likely to experience method failure. ${ }^{[1]}$ The intrauterine contraceptive device (IUCD) has an extremely high efficacy rate compared with other methods of contraception. The IUCD is not dependent on patient participation for correct use, which results in a very low failure rate, ${ }^{[6]}$ estimated to be 2 - 3 pregnancies per 100 woman-years. ${ }^{[7]}$
Recently the SA government has decided to introduce long-acting contraceptives, particularly the $\mathrm{Cu} 380 \mathrm{IUCD}$, in the public health sector. These devices are free in public hospitals and clinics and can be inserted at any time, in the immediate postpartum period, after abortion or electively when the woman wishes. ${ }^{[8]}$

\section{Objective}

To evaluate knowledge about and attitudes towards the IUCD among women in the reproductive age group in a resourceconstrained setting.

\section{Methods}

We performed a survey of women attending antenatal/postnatal clinics at Northdale Hospital (NDH) and East Boom Community Health Centre (CHC) in Pietermaritzburg, SA. Both facilities offer maternity services including antenatal, postnatal, prevention of mother-to-child transmission of HIV and family planning services.

The study cohort consisted of women attending the public sector antenatal/postnatal clinics. Eligible participants were women who had attended the antenatal clinic at least once and who had heard about different methods of contraception, including the IUCD. Participants were excluded if they could not understand English or Zulu. They were also excluded if they had never heard of the IUCD. One client was excluded because of language and 26 clients because they had never heard of the IUCD before.

The sampling was a convenience one, and we interviewed 150 women in total. 
A brief explanation of the study was given to eligible participants and consent was obtained from all those who agreed to participate.

The researcher administered a structured questionnaire. Information on participants' sociodemographic characteristics, previous contraceptive methods, knowledge and attitudes towards the IUCD and source of information was collected from October 2013 to March 2014. Data were analysed using the Statistica data analysis software system, version 12 (StatSoft Inc., USA).

Participants were categorised into three groups according to their parity. The first group (group A) comprised all participants who were nulliparous. Group B included all participants who were para 1 or 2 , and group $\mathrm{C}$ all those who were para 3 or more. The researcher expected women with high parity to have better knowledge about the device than those with low parity. Counselling and information about different methods of contraception are given to women during each antenatal/ postnatal visit.

Summary statistics were estimated for all participants. Descriptive results were compared by parity status, HIV status and facility using the $\chi 2$ test. The differences between groups were considered significant if the $p$-value was $<0.05$.

The research was approved by the Biomedical Research Ethics Committee of the University of KwaZulu-Natal (BE 302/13), the KwaZulu-Natal Department of Health (HRKM 298/13) and the Umgungundlovu Health District office.

\section{Results \\ Sociodemographic characteristics}

Most participants were in their twenties, with a mean age of $25 ; 76.7 \%(n=115)$ were $<30$ years old, $16.0 \%(n=24)$ were teenagers, and less than $5 \%(n=7)$ were aged 35 years or more (Table 1 ).

Most participants were single (69.3\%, $n=104)$ with only $17.3 \%(n=26)$ married and $13.3 \%(n=20)$ in a stable relationship.

Most participants had some form of formal education: $5.3 \%$ reported that they had never been to school, $52.7 \%$ had attended school up to secondary level, 9.3\% had only primary school education and $32.7 \%$ had tertiary education. At the time of the survey, $52.7 \%$ of participants were unemployed, $18.7 \%$ were still studying and $28.7 \%$ had a job.
Most were HIV-negative (62.7\%, $n=94)$. All HIV-positive participants except one were on antiretroviral therapy at the time of the interview (Table 1).

\section{Previous use of contraception and fertility desire}

The contraceptive injection was the type of contraception with which participants were most familiar; $46.0 \%$ had some experience with contraceptive injections, while only $2.7 \%$ had used the IUCD before, and $18.0 \%$ of participants had used no form of contraception before. Condoms alone were used as a form of contraceptive method by $26.0 \%$ of participants.

With regard to future plans to conceive, of those participants who had a plan, most indicated they would like to wait for at least
3 years before their next pregnancy; $48.7 \%$ were unsure or had no clear plan at the time of the interview (Table 1).

\section{Knowledge about the IUCD}

The study showed no significant difference among the three parity groups in terms of knowledge about the IUCD ( $p>0.05$ for all the questions).

All the participants interviewed knew that the device is used to prevent pregnancy. The majority of them knew that it does not protect against HIV, and there was no significant difference between the three groups regarding their answers. It is of concern, however, that some participants (29.3\%,n=44) could not state with confidence that the device does not prevent HIV transmission. Of these 44 participants,

Table 1. Demographic characteristics and previous experience with contraceptives

\begin{tabular}{|c|c|c|c|c|}
\hline & $\begin{array}{l}\text { Parity group A } \\
(N=50)\end{array}$ & $\begin{array}{l}\text { Parity group B } \\
(N=50)\end{array}$ & $\begin{array}{l}\text { Parity group C } \\
(N=50)\end{array}$ & $\begin{array}{l}\text { Total } \\
(N=150)\end{array}$ \\
\hline Age (years), mean & 21 & 24 & 29 & 25 \\
\hline \multicolumn{5}{|l|}{ Marital status, $n(\%)$} \\
\hline Single & $39(78.0)$ & $35(70.0)$ & $30(60.0)$ & $104(69.3)$ \\
\hline Married & $2(4.0)$ & $10(20.0)$ & $14(28.0)$ & $26(17.3)$ \\
\hline Stable relationship & $9(18.0)$ & $5(10.0)$ & $6(12.0)$ & $20(13.3)$ \\
\hline \multicolumn{5}{|l|}{ Education level, $n(\%)$} \\
\hline No schooling & $1(2.0)$ & $2(4.0)$ & $5(10.0)$ & $8(5.3)$ \\
\hline Grades $1-7$ & $4(8.0)$ & $2(4.0)$ & $8(16.0)$ & $14(9.3)$ \\
\hline Grades $8-12$ & $29(58.0)$ & $24(48.0)$ & $26(52.0)$ & $79(52.7)$ \\
\hline Tertiary & $16(32.0)$ & $22(44.0)$ & $11(22.0)$ & $49(32.7)$ \\
\hline \multicolumn{5}{|l|}{ Employment, $n(\%)$} \\
\hline Unemployed & $24(48.0)$ & $24(48.0)$ & $31(62.0)$ & $79(52.7)$ \\
\hline Employed & $12(24.0)$ & $13(26.0)$ & $18(36.0)$ & $43(28.7)$ \\
\hline Student & $14(28.0)$ & $13(26.0)$ & $1(2.0)$ & $28(18.7)$ \\
\hline \multicolumn{5}{|l|}{ HIV status, $n(\%)$} \\
\hline Positive & $15(30.0)$ & $23(46.0)$ & $18(36.0)$ & $56(37.3)$ \\
\hline Negative & $35(70.0)$ & $27(54.0)$ & $32(64.0)$ & $94(62.7)$ \\
\hline \multicolumn{5}{|c|}{ Next pregnancy plan, $n(\%)$} \\
\hline$<12$ months & $0(0.0)$ & $0(0.0)$ & $0(0.0)$ & $0(0.0)$ \\
\hline $12-24$ months & $1(2.0)$ & $1(2.0)$ & $3(6.0)$ & $5(3.3)$ \\
\hline 25 - 36 months & $4(8.0)$ & $3(6.0)$ & $2(4.0)$ & $9(6.0)$ \\
\hline$>36$ months & $23(46.0)$ & $20(40.0)$ & $20(40.0)$ & $63(42.0)$ \\
\hline Unsure & $22(44.0)$ & $26(52.0)$ & $25(50.0)$ & $73(48.7)$ \\
\hline \multicolumn{5}{|c|}{$\begin{array}{l}\text { Recently used contraceptive, } \\
n(\%)\end{array}$} \\
\hline The Pill & $2(4.0)$ & $4(8.0)$ & $5(10.0)$ & $11(7.3)$ \\
\hline Injectable & $16(32.0)$ & $19(38.0)$ & $34(68.0)$ & $69(46.0)$ \\
\hline IUCD & $1(2.0)$ & $1(2.0)$ & $2(4.0)$ & $4(2.7)$ \\
\hline Condoms & $19(38.0)$ & $14(28.0)$ & $6(12.0)$ & $39(26.0)$ \\
\hline None & $12(24.0)$ & $12(24.0)$ & $3(6.0)$ & $27(18.0)$ \\
\hline
\end{tabular}


$45.5 \%$ ( $n=20)$ belonged to group C, $31.8 \%$ ( $n=14)$ to group B and $22.7 \%(n=10)$ to the nulliparous group (Table 2, Fig. 1). While $70.7 \%(n=106)$ of all participants could tell without hesitation that the device does not prevent transmission of HIV, there was no significant difference when the three groups were compared $(p=0.086)$.

Only $40.7 \%(n=61)$ of all participants knew that HIV-positive women can safely use the IUCD. Participants in the group with high parity who knew that HIV-positive women can also use the device represented $31.2 \%(n=19)$ compared with $36.1 \% \quad(n=22)$ in the nulliparous group and $32.8 \%(n=20)$ in group B. The difference between these groups was not significant $(p=0.82$ ).

Among participants who knew that HIV-positive women can use the device safely, $59.0 \% \quad(n=36)$ were HIV-negative and $41.0 \%(n=25)$ were HIV-positive. Of the 89 participants who said that HIVpositive women should not use the IUCD, 65.2\% ( $n=58$ ) were HIV-negative and $34.8 \%$ $(n=31)$ were HIV-positive.

Of all the participants, $75.3 \%$ were uncertain about whether the IUCD causes heavy bleeding. The difference in answers between the three groups was significant $(p=0.03)$, with more women of high parity than nulliparous clients considering the device to be a cause of bleeding.

Only $36.7 \%$ of the participants $(n=55)$ knew that the device does not stop fertility indefinitely: $34.6 \%(n=19)$ of these women belonged to group C, another 34.6\% ( $n=19)$ to group B and $30.9 \%(n=17)$ to group A. However, the dfference between the groups was not significant $(p=0.89)$.

Knowledge about the quick return to fertility once the IUCD has been removed was very poor. Only $12.0 \% \quad(n=18)$ of participants answered this question correctly; of these $50.0 \%$ ( $n=9)$ belonged to group C, $27.8 \%(n=5)$ to group B and $22.2 \%$ $(n=4)$ to group A. The difference between the groups was not significant $(p=0.27$ ).

One-third of all participants knew that the IUCD can be inserted in the immediate postpartum period: $36.0 \%(n=18)$ belonged to group C, another $36.0 \%(n=18)$ to group $\mathrm{B}$ and $28.0 \%(n=14)$ to group A. More participants with higher parity than nulliparous participants knew that the device may be inserted after delivery $(p=0.61)$.

Only $26.7 \%$ of the participants $(n=40)$ knew that the $\mathrm{Cu}$ T380A could be used for 10 years. With most women planning for their next pregnancy in the next 3

Table 2. Knowledge about the IUCD per parity group

\begin{tabular}{|c|c|c|c|c|c|}
\hline & $\begin{array}{l}\text { Parity group A } \\
(N=50) \\
n(\%)^{\star}\end{array}$ & $\begin{array}{l}\text { Parity group B } \\
(N=50) \\
n(\%)^{*}\end{array}$ & $\begin{array}{l}\text { Parity group C } \\
(N=50) \\
n(\%)^{*}\end{array}$ & Total, $N$ & $p$-value \\
\hline \multicolumn{6}{|c|}{ Does not prevent HIV } \\
\hline Know & $40(37.7)$ & $36(34.0)$ & $30(28.3)$ & 106 & \multirow[t]{2}{*}{0.08646} \\
\hline Do not know & $10(22.7)$ & $14(31.8)$ & $20(45.5)$ & 44 & \\
\hline \multicolumn{6}{|c|}{ HIV+ women can use IUCD } \\
\hline Know & $22(36.1)$ & $20(32.8)$ & $19(31.2)$ & 61 & \multirow[t]{2}{*}{0.82442} \\
\hline Do not know & $28(31.5)$ & $30(33.7)$ & $31(34.8)$ & 89 & \\
\hline \multicolumn{6}{|c|}{ Does not cause heavy bleeding } \\
\hline Know & $18(48.7)$ & $7(18.9)$ & $12(32.4)$ & 37 & \multirow[t]{2}{*}{0.03603} \\
\hline Do not know & $32(28.3)$ & $43(38.1)$ & $38(33.6)$ & 113 & \\
\hline \multicolumn{6}{|c|}{ Does not stop fertility } \\
\hline Know & $17(30.9)$ & $19(34.6)$ & $19(34.6)$ & 55 & \multirow[t]{2}{*}{0.89094} \\
\hline Do not know & $33(34.7)$ & $31(32.6)$ & $31(32.6)$ & 95 & \\
\hline \multicolumn{6}{|c|}{ Quick fertility return } \\
\hline Know & $4(22.2)$ & $5(27.8)$ & $9(50.0)$ & 18 & \multirow[t]{2}{*}{0.27902} \\
\hline Do not know & $46(34.8)$ & $45(34.1)$ & $41(31.1)$ & 132 & \\
\hline \multicolumn{6}{|c|}{ Postpartum insertion } \\
\hline Know & $14(28.0)$ & $18(36.0)$ & $18(36.0)$ & 50 & \multirow[t]{2}{*}{0.61407} \\
\hline Do not know & $36(36.0)$ & $32(32.0)$ & $32(32.0)$ & 100 & \\
\hline \multicolumn{6}{|c|}{ Can keep up to 10 years } \\
\hline Know & $13(32.5)$ & $16(40.0)$ & $11(27.5)$ & 40 & \multirow[t]{2}{*}{0.52437} \\
\hline Do not know & $37(33.6)$ & $34(30.9)$ & $39(35.5)$ & 110 & \\
\hline
\end{tabular}

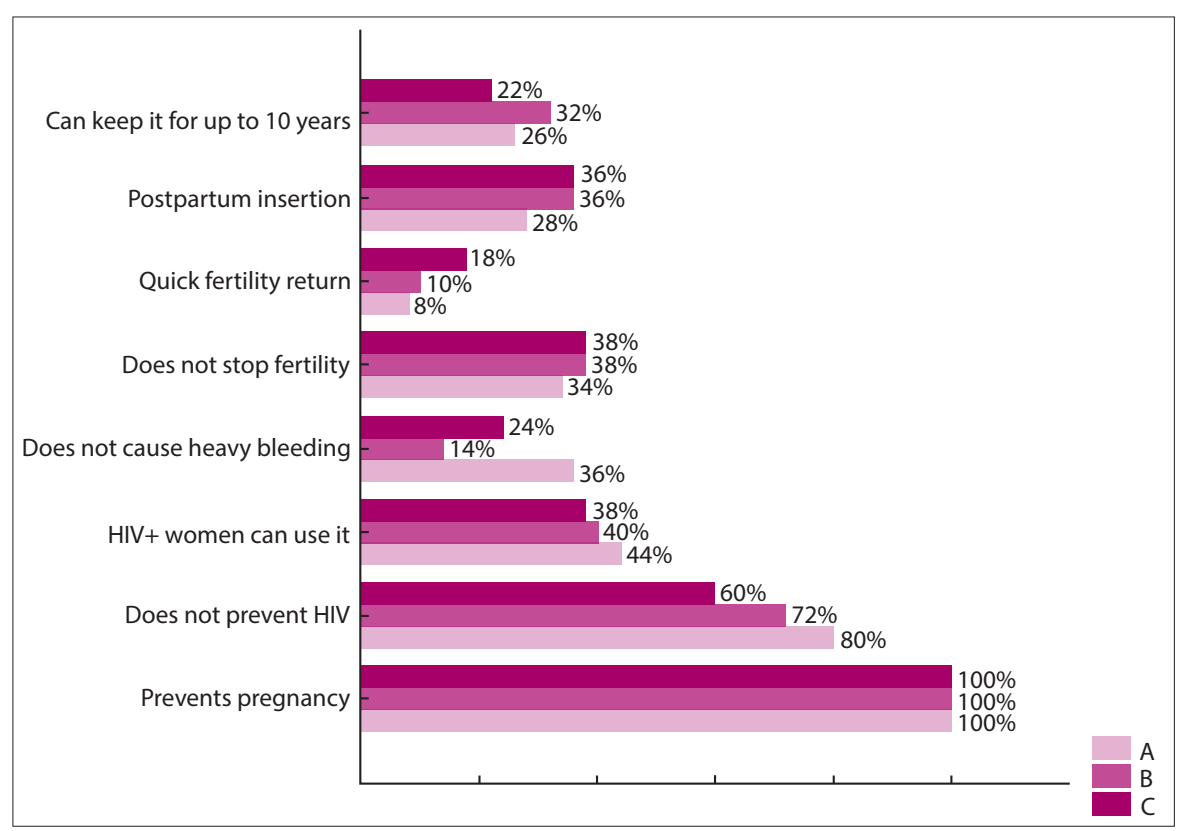

Fig. 1. Knowledge in each parity group. $(A=$ nulliparous; $B=$ para $1-2 ; C=$ para $\geq 3$. $)$

years, we expected participants to know about duration of use, especially those in group C. Of these $26.7 \%$, only $27.5 \%$ $(n=11)$ belonged to group C, $40.0 \%(n=16)$ to group $\mathrm{B}$ and $32.5 \%(n=13)$ to group A. However, the difference between the groups was not statistically significant $(p=0.52)$.

When the two facilities included in the study were compared, there was a statistical difference $(p=0.02)$ in respect of the response regarding duration of use. Among those who 
knew the correct duration of use only $30.0 \%$ $(n=12)$ were from the clinic compared with $70.0 \%(n=28)$ from the hospital.

In general, knowledge about the IUCD among women visiting public sector facilities is very poor. Information that should be part of every counselling session on contraception, such as the duration of use or the time of insertion, as it can influence client choice, is ignored. Even among women with higher parity knowledge is still poor.

Knowledge was poorer at the East Boom $\mathrm{CHC}$ compared with NDH. All participants knew that the device prevents pregnancy, but beyond this information knowledge is poor, as shown in Fig. 2.

\section{Attitudes towards the IUCD}

Regarding attitudes towards the IUCD, the study showed that there are four concerns about this type of contraception that need to be addressed during every teaching and counselling opportunity, namely fear of pain, fear of cancer, concern about the device's interfering with sexual activity, and fear of womb perforation. Forty percent of all participants expressed concern about pain during insertion, and more than 30\% expressed fear that having the device in the uterus would cause genital cancer and fear of womb perforation. The belief that the device would interfere with normal sexual activity was expressed by more than $30 \%$ of participants.

Less than $10 \%$ of participants would not consider using the device because of their cultural or religious beliefs.

Twenty-four percent $(n=36)$ of participants thought that the device was only for multiparous women (Table 3 ).

Almost 21\% $(n=31)$ of all participants believed their partner would stop using condoms if they used the device. This concern clearly demonstrates partners' lack of understanding of the reason for the continued need for condom use to prevent sexually transmitted diseases. It also elucidates the need for couple counselling, which may be a challenge to achieve in the public sector. In general there were some negligible differences among the three parity groups, as shown in Table 3, except for the issue regarding the fear of perforation. More nulliparous participants (46.8\%) expressed fear of perforation compared with multiparous clients.

\section{Source of information}

The main source of information was the

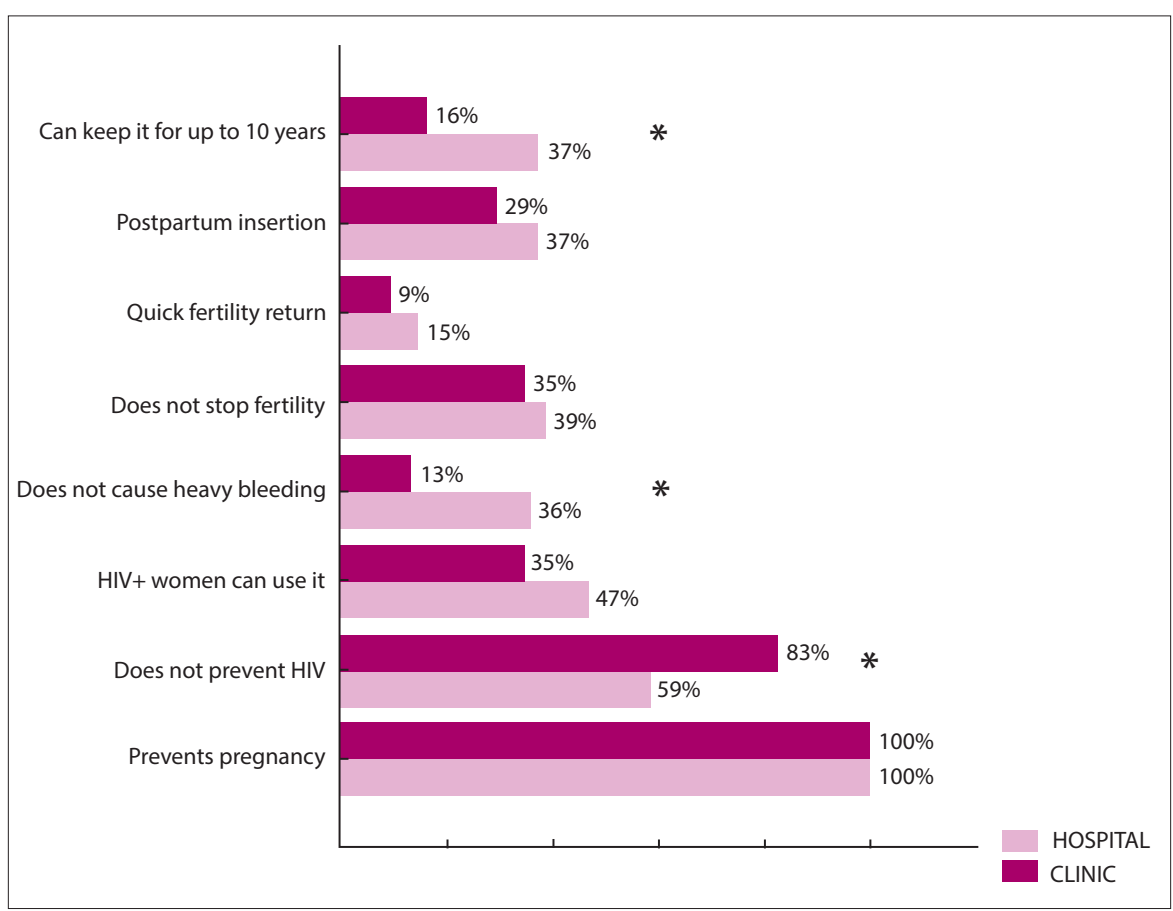

Fig. 2. Knowledge per facility. $\left({ }^{*}=\right.$ significant difference. $)$

clinic; $77.3 \% \quad(n=116)$ of all participants had acquired their information about the IUCD from the clinic during teaching and counselling sessions. Twelve percent $(n=18)$ acquired their information from friends, $8.0 \%(n=12)$ from school, $5.3 \%(n=8)$ from the media and only $2.7 \%(n=4)$ from family members. It is worthwhile to note that some participants had more than one source of information.

\section{Discussion}

The study has shown that there is poor knowledge about the IUCD among women using public sector facilities. There was a negligible difference among participants based on parity status, contrary to the researchers' expectation that women of higher parity might have a good knowledge of the long-acting reversible contraceptive (LARC) device.

Credé et al. ${ }^{[3]}$ documented poor knowledge of LARC methods in their study conducted in Cape Town. However, this study was done before the government embarked on the process of promoting the IUCD. Some years down the road, knowledge is still poor and uptake of the device low. Only $2.7 \%$ of participants interviewed had used the IUCD before and most of them had experience with the injectable Depo-Provera. Most participants in our study expressed the desire to space their children, and were ready to wait at least 3 years before their next pregnancy, showing a need for LARC methods. It seems that clinic staff prefer to recommend the injectable method and in some situations just prescribe it, especially in the postnatal clinics. The study has shown a need for the facilities to relook at their method of promoting the device, especially as the Department of Health is in the process of introducing another LARC method, i.e. implants (Implanon NXT). Following a $12 \%$ pregnancy rate reported in a study from Swaziland among users of Implanon who were HIV-positive and also taking enzyme-inducing efavirenz as antiretroviral therapy, ${ }^{[9]}$ the SA government has issued a caution regarding Implanon. Although the numbers were small, it has at present recommended the use rather of Depo-Provera in this group, as the increased metabolism of the active constituent is not so great (National Department of Health circular, available on the Southern African HIV Clinicians Society home page www.sahivsoc.org).

The participants interviewed were ignorant about most information regarding the device. We believe that the facilities should make a clear plan to correct this situation, as most of this information will influence not only uptake of the device but also adherence. Nulliparous women and those with few children would like to be reassured, for example, that the return to fertility is relatively quick after removal of the IUCD. Very few participants (12\%) 


\begin{tabular}{|c|c|c|c|c|c|}
\hline & $\begin{array}{l}\text { Parity group A }(N=50) \\
n(\%)^{*}\end{array}$ & $\begin{array}{l}\text { Parity group } B(N=50) \\
n(\%)^{*}\end{array}$ & $\begin{array}{l}\text { Parity group C }(N=50) \\
n(\%)^{*}\end{array}$ & Total, $N$ & $p$-value \\
\hline \multicolumn{6}{|c|}{ Fear partner stops condoms } \\
\hline Agree & $10(32.3)$ & $8(25.8)$ & $13(41.9)$ & 31 & 0.6185 \\
\hline Do not agree & $36(33.3)$ & $37(34.3)$ & $35(32.4)$ & 108 & \\
\hline No opinion & $4(36.4)$ & $5(45.5)$ & $2(18.2)$ & 11 & \\
\hline \multicolumn{6}{|c|}{ Causes sexually transmitted diseases } \\
\hline Agree & $13(56.5)$ & $5(21.7)$ & $5(21.7)$ & 23 & 0.1060 \\
\hline Do not agree & $34(30.1)$ & $41(36.3)$ & $38(33.6)$ & 113 & \\
\hline No opinion & $3(21.4)$ & $4(28.6)$ & $7(50.0)$ & 14 & \\
\hline \multicolumn{6}{|c|}{ Interferes with sex } \\
\hline Agree & $21(43.8)$ & $11(22.9)$ & $16(33.3)$ & 48 & 0.2420 \\
\hline Do not agree & $26(28.9)$ & $33(36.7)$ & $31(34.4)$ & 90 & \\
\hline No opinion & $3(25.0)$ & $6(50.0)$ & $3(25.0)$ & 12 & \\
\hline \multicolumn{6}{|c|}{ Fear of perforation } \\
\hline Agree & $22(46.8)$ & $10(21.3)$ & $15(31.9)$ & 47 & 0.0086 \\
\hline Do not agree & $27(31.8)$ & $30(35.3)$ & $28(32.9)$ & 85 & \\
\hline No opinion & $1(5.6)$ & $10(55.6)$ & $7(38.9)$ & 18 & \\
\hline \multicolumn{6}{|l|}{ Fear of cancer } \\
\hline Agree & $22(44.0)$ & $11(22.0)$ & $17(34.0)$ & 50 & 0.1481 \\
\hline Do not agree & $23(26.1)$ & $35(39.8)$ & $30(34.1)$ & 88 & \\
\hline No opinion & $5(41.7)$ & $4(33.3)$ & $3(25.0)$ & 12 & \\
\hline \multicolumn{6}{|l|}{ Fear of pain } \\
\hline Agree & $21(35.0)$ & $17(28.3)$ & $22(36.7)$ & 60 & 0.7511 \\
\hline Do not agree & $26(33.3)$ & $29(37.2)$ & $23(29.5)$ & 78 & \\
\hline No opinion & $23(25.0)$ & $4(33.3)$ & $5(41.7)$ & 12 & \\
\hline \multicolumn{6}{|c|}{ Only for multiparous } \\
\hline Agree & $11(30.6)$ & $12(33.3)$ & $13(36.1)$ & 36 & 0.9738 \\
\hline Do not agree & $36(34.6)$ & 35 (33.7) & $33(31.7)$ & 104 & \\
\hline No opinion & $3(30.0)$ & $3(30.0)$ & $4(40.0)$ & 10 & \\
\hline \multicolumn{6}{|c|}{ Fear of gaining weight } \\
\hline Agree & $10(27.8)$ & $14(38.9)$ & $12(33.3)$ & 36 & 0.3014 \\
\hline Do not agree & $38(38.0)$ & $29(29.0)$ & $33(33.0)$ & 100 & \\
\hline No opinion & $2(14.3)$ & $7(50.0)$ & $5(35.7)$ & 14 & \\
\hline \multicolumn{6}{|l|}{ It is like abortion } \\
\hline Agree & $2(18.2)$ & $4(36.4)$ & $5(45.5)$ & 11 & 0.1957 \\
\hline Do not agree & $48(35.0)$ & $46(33.6)$ & $43(31.4)$ & 137 & \\
\hline No opinion & 0 & 0 & $2(100.0)$ & 2 & \\
\hline \multicolumn{6}{|l|}{ It is a $\sin$} \\
\hline Agree & $2(22.2)$ & $3(33.3)$ & $4(44.4)$ & 9 & 0.5762 \\
\hline Do not agree & 47 (33.6) & 47 (35.6) & $46(32.9)$ & 140 & \\
\hline No opinion & $1(100.0)$ & 0 & 0 & 1 & \\
\hline \multicolumn{6}{|l|}{ Religion is against } \\
\hline Agree & $3(21.4)$ & $7(50.0)$ & $4(28.6)$ & 14 & 0.4482 \\
\hline Do not agree & $47(35.1)$ & $42(31.3)$ & 45 (33.6) & 134 & \\
\hline No opinion & 0 & $1(50.0)$ & $1(50.0)$ & 2 & \\
\hline \multicolumn{6}{|c|}{ Tradition is against } \\
\hline Agree & $4(28.6)$ & $4(28.6)$ & $6(42.9)$ & 14 & 0.7376 \\
\hline Do not agree & $46(33.8)$ & $46(33.8)$ & $44(32.4)$ & 136 & \\
\hline No opinion & 0 & 0 & 0 & 0 & \\
\hline
\end{tabular}


knew this fact. This finding was similar to that of Credé et al. ${ }^{[3]}$ in Cape Town. This may negatively affect uptake, not only among women of low parity but also among those who are advanced in age. Clinics should ensure that issues regarding fertility return are dealt with during counselling, to improve uptake of the device.

Most women interviewed would like to wait for at least 3 years before their next pregnancy. We believe that they would like to know for how long it is safe to have a foreign body inserted in their uterus. Unfortunately only $26.7 \%$ of women interviewed knew that it is actually safe to use the IUCD for up to 10 years. Credé et al. ${ }^{[3]}$ found that more than half of their participants did not know that they could use the device for 10 years. Studies conducted in SA by Gutin et al. ${ }^{[10]}$ and in the USA by Whitaker et al. ${ }^{[11]}$ reported that participants mentioned as an advantage the fact that the IUCD could be used for a long time.

With the high prevalence of HIV in SA, and particularly in KwaZulu-Natal, the researchers expected that most women, regardless of their HIV status, would know that HIV-positive women can safely use the IUCD. Only $41.0 \%$ of all participants knew that HIV patients can safely use it. Credé et al. ${ }^{[3]}$ reported that more than half of their participants did not know that HIV-positive patients could safely use the IUCD. In our study, only $44.6 \%$ of HIVpositive women knew that it was safe for them to use the device, and 38.3\% of HIV-negative participants knew that HIV-positive women can use it. It is also crucial to inform women that, unlike barrier contraceptives, IUCDs do not provide protection against HIV or other sexually transmitted diseases. ${ }^{[7]}$

We believe one of the ways to improve the situation is to prepare a structured teaching presentation on contraception including all these facts to be used as a template. Clinics should refrain from prescribing one type of contraceptive; women should be allowed to choose freely after discussion of appropriate information. In fact, according to the World Health Organization's evidencebased medical eligibility criteria for contraceptive use, LARC methods have few contraindications. Because of this and the potential to reduce unintended pregnancy rates, the American Congress of Obstetricians and Gynecologists suggests that LARC methods should be offered as first-line contraceptive methods and encouraged as options for most women. ${ }^{[12]}$

There were few misconceptions about the IUCD as documented in the results above. Gutin et al. ${ }^{[10]}$ also found that there was poor knowledge about the IUCD among SA women but few misconceptions. Neither religion nor traditional beliefs seem to be an obstacle when it comes to the use of the IUCD. The only elements that seem to be of concern are fear of pain, fear of cancer, fear of womb perforation and interference with sexual activity, even though none of these was an issue in more than $40 \%$ of the participants. These concerns should be addressed during every counselling session if we expect to improve uptake of the device.

The answers from the hospital group showed greater knowledge and more accurate attitudes about IUCDs than those from the clinic group. The difference was significant in some cases, as shown in Fig. 2. This may be explained by the fact that the clinic had not yet started offering insertion of the IUCD and were referring their clients to the hospital.

Most of the participants (77.3\%) acquired their knowledge from the clinic, indicating the need for the facilities to ensure that the information they are transmitting is comprehensive. None of the participants mentioned the leaflet as a source of information. The clinics should perhaps try to use leaflets in addition to the usual form of teaching. The advantage of this is that the leaflet can be taken at home and be shared with the partner/family, especially in an environment where men do not attend family planning clinics. Partner/family disapproval can influence uptake and reduce adherence. ${ }^{[13,14]}$

\section{Study limitations and strengths}

The findings of this study are based on a convenience sample of women from a specific area, Pietermaritzburg. The transferability of the results may therefore be limited. However, the study gave us a picture of the current situation in the public sector in this area.

This is the first study to investigate attitudes and knowledge about the IUCD among clients in this area. It has identified the main misconceptions among clients and showed that knowledge among clients is poor. The findings should be used by clinics to improve the situation.

\section{Conclusion}

This survey documents poor knowledge about the IUCD among women using the public health sector in Pietermaritzburg, SA. A notable finding of our study was fewer misconceptions compared with those documented in studies conducted in other parts of the country. This finding, coupled with the fact that most of the participants rely on the clinic as their source of information, should be seen as an opportunity to improve the situation. Diversification of methods of teaching and the involvement of the partner/family, either through direct contact or via documents such as leaflets, may help in terms of the uptake of the device and adherence.

1. Ong J, Temple-Smith M, Wong WCW, McNamee K, Fairley C. Contraceptive matters: indicators of poor usage of contraception in sexually active women attending family planning clinic in Victoria Australia. BMC Public Health 2012;12(1):1108-1117. [http://www.biomedcentral.com/1471 2458/12/1108]

2. Frost JJ, Darroch JE. Factors associated with contraceptive choice and inconsistent method use, United States, 2004. Perspectives on Sexual and Reproductive Health 2008;40(2):94-104. [http:// dx.doi.org/10.1363/4009408]

3. Credé S, Hoke T, Constant D, Green MS, Moodley J, Harries J. Factors impacting knowledge and use of long acting and permanent contraceptive methods by postpartum HIV positive and negative women in Cape Town, South Africa: A cross sectional study. BMC Public Health 2012;12(1):197205. [http://www.biomedcentral.com/1471-2458/12/197]

4. Department of Health, Republic of South Africa. National Contraception Clinical Guidelines. 2012. http://www.doh.gov.za/docs/policy/2013/contraception_clinical_guidelines_28jan2013 (accessed 13 March 2013).

5. Patel CJ, Kooverjee T. Abortion and contraception: Attitudes of South African university students. Health Care For Women International 2009;30(6):550-568. [http://dx.doi. org/10.1080/07399330902886105]

6. Chen AY, Baldwin S. Intrauterine devices. In: Shoupe D, Kjos SL, eds. Handbook of Contraception: A Guide for Practical Management. New York: Humana Press, 2006:129-145.

7. Anthony A, Repke JT. Puerperal problems. In: James D, Steer PJ, Weiner CP, Gonik B, Crowther CA, Robson SC, eds. High Risk Pregnancy: Management Options. New York: Elsevier Saunders: 2011:1313-1329.

8. Whiteman MK, Tyler CP, Folger SG, Gaffield ME, Curtis KM. When can a woman have an intrauterine device inserted: A systematic review. Contraception 2013;87(5):666-673. [http:// dx.doi.org/10.1016/j.contraception.2012.08.015]

9. Perry SH, Swamy P, Preidis GA, Mwanyumba A, Motsa N, Sarero H. Implementing the Jadelle implant for women living with HIV in a resource-limited setting: Concerns for drug interactions leading to unintended pregnancies. AIDS 2014;28(5):791-793. [http://dx.doi.org/10.1097/ QAD.0000000000000177]

10. Gutin SA, Mlobeli R, Moss M, Buga G, Morroni C. Survey of knowledge, attitudes and practices surrounding the intrauterine device in South Africa. Contraception 2011;83(2):145-150. [http:// dx.doi.org/10.1016/j.contraception.2010.07.009]

11. Whitaker AK, Johnson LM, Harwood B, Chiappetta L, Creinin MD, Gold MA. Adolescent and young adult women's knowledge of and attitudes toward the intrauterine device. Contraception 2008;78(3):211-217. [http://dx.doi.org/10.1016/j.contraception.2008.04.119]

12. American Congress of Obstetricians and Gynecologists (ACOG). Increasing use of contraceptive implants and intrauterine devices to reduce unintended pregnancy. 2011. http://www.acog.org/ resources_And_Publications/committee_opinions (accessed 21 May 2014).

13. Weston MRS, Martins SL, Neustadt AB, Gilliam ML. Factors influencing uptake of intrauterine devices among postpartum adolescents: A qualitative study. Am J Obstet Gynecol 2012;206(1):40. el-40.e7. [http://dx.doi.org/10.1016/j.ajog.2011.06.094]

14. Haddad LB, Cwiak C, Jamieson DJ, et al. Contraceptive adherence among HIV-infected women in Malawi: A randomized controlled trial of the copper intrauterine device and depot medroxyprogesterone acetate. Contraception 2013;88(6):737-743. [http://dx.doi.org/10.1016/j. contraception.2013.08.006 